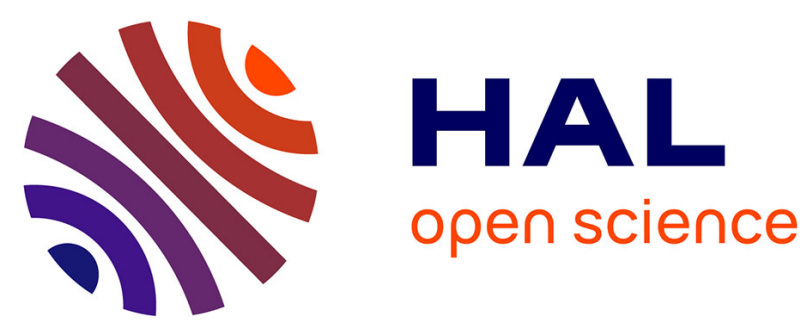

\title{
A study of floral shape variation in Delphinieae (Ranunculaceae) using geometric morphometrics on herbarium specimens
}

Yiyun Chen, Florian Jabbour, Andriy Novikov, Wei Wang, Sylvain Gerber

\section{- To cite this version:}

Yiyun Chen, Florian Jabbour, Andriy Novikov, Wei Wang, Sylvain Gerber. A study of floral shape variation in Delphinieae (Ranunculaceae) using geometric morphometrics on herbarium specimens. Botany Letters, 2018, 165 (3-4), pp.368-376. 10.1080/23818107.2018.1427145 . hal-02187075

\section{HAL Id: hal-02187075 \\ https://hal.sorbonne-universite.fr/hal-02187075}

Submitted on 17 Jul 2019

HAL is a multi-disciplinary open access archive for the deposit and dissemination of scientific research documents, whether they are published or not. The documents may come from teaching and research institutions in France or abroad, or from public or private research centers.
L'archive ouverte pluridisciplinaire HAL, est destinée au dépôt et à la diffusion de documents scientifiques de niveau recherche, publiés ou non, émanant des établissements d'enseignement et de recherche français ou étrangers, des laboratoires publics ou privés. 


\section{A study of floral shape variation in Delphinieae (Ranunculaceae) using geometric morphometrics on herbarium specimens}

Yiyun Chen ${ }^{\mathrm{a}}$, Florian Jabbour ${ }^{\mathrm{a}}$, Andriy Novikov ${ }^{\mathrm{b}}$, Wei Wang ${ }^{\mathrm{c}}$, Sylvain Gerber ${ }^{\mathrm{d}}$

${ }^{a}$ Muséum national d'Histoire naturelle, Institut de Systématique, Évolution, Biodiversité, UMR 7205 ISYEB MNHN/CNRS/UPMC/ EPHE, Sorbonne Universités, 57 rue Cuvier, CP 39, 75005 Paris, France; 'b State Natural History Museum NAS of Ukraine, Teatralna str. 18, 79008 Lviv, Ukraine; 'State Key Laboratory of Systematic and Evolutionary Botany, Institute of Botany, Chinese Academy of Sciences, Beijing 100093, China; and University of Chinese Academy of Sciences, Beijing 100049, China; ${ }^{d}$ Muséum national d'Histoire naturelle, Institut de Systématique, Évolution, Biodiversité, UMR 7205 ISYEB MNHN/CNRS/UPMC/ EPHE, Sorbonne Universités, 57 rue Cuvier, CP 50, 75005 Paris, France

Contact: Florian Jabbour, fjabbour@mnhn.fr

Word count: 6269 


\begin{abstract}
The variation in the shape of flowers, the reproductive structures of angiosperms, is generally investigated in a qualitative way, or using multivariate statistical analyses of distance data (i.e. traditional morphometrics). In this study, we evaluate the application of geometric morphometric methods to flowers of herbarium specimens, a material that is still being massively overlooked as far as these methods are concerned. Flowers of Delphinieae (Ranunculaceae) are synorganised: the spurred and nectariferous dorsal petals are nested within the spur or hood of the dorsal sepal. The study of synorganised structures is challenging, and geometric morphometric-oriented investigation may provide working hypotheses for an evo-devo exploration of such hyperorgan formation. We analyze here the floral shape of Delphinieae using geometric morphometric methods and demonstrate the effectiveness of these methods on dry and compressed flowers. We also show the diagnostic value of the dorsal half of the perianth of the Delphinieae flower, and suggest some trends to help design future studies on the evo-devo of spur formation and the co-evolution of Delphinieae flowers with their pollinators.
\end{abstract}

\title{
Keywords
}

Aconitum; Delphinium; Flower morphology; Nectar spur; Staphisagria; Taxonomy

\section{Introduction}

The extent of shape variation in angiosperm reproductive structures is remarkable (Endress 1994, 1999; Sauquet et al. 2017). Most botanical studies aiming at quantifying the variation in floral shape have so far employed traditional morphometrics, the multivariate statistical analysis of distance data (e.g. Nagahama, Anton, and Norrmann 2014; Chartier et al. 2016), while modern geometric morphometric methods (GMM) have remained surprisingly 
underused. However, the development of geometric morphometrics since the nineties, based on the spatial relationships among homologous anatomical landmarks, has revolutionized the study of biological shape variation (Rohlf and Marcus 1993). The main advantage of geometric morphometrics over traditional morphometrics is that the geometry of the biological structure under study (as captured by the relative positions of landmarks) is preserved throughout the analyses, allowing for insightful visualizations and refined interpretations of morphological patterns (Adams, Rohlf, and Slice2004).

Among the botanical studies that have applied geometric morphometrics, some have used landmark data to study shape variation in fresh plant material in two dimensions (e.g. leaves: Jensen, Ciofani, and Miramontes 2002; or seeds: Jacques and Zhou 2010) or fresh flowers in 2D (Gómez, Perfectti, and Camacho 2006; Abdelaziz et al. 2011; Savriama et al. 2012; Fernández-Mazuecos et al. 2013; Gardner et al. 2016) or 3D (van der Niet et al. 2010; Wang et al. 2015). However, fresh plant material can be difficult to gather and conserve over the time of the study. Here, we evaluated the application of GMM to dry and compressed flowers of herbarium specimens, a material that is still being massively overlooked (but see Shipunov and Bateman 2005, where GMM were applied to flowers dried for the purpose of the study) compared with dry leaves from herbarium specimens (Viscosi and Cardini 2011; Cope et al. 2012).

Synorganisation is defined as the intimate structural connection of two or several neighboring floral organs to form a functioning system or apparatus ("hyperorgan"). It may occur through congenital or postgenital fusion or by coordination of organs without fusion (Specht and Bartlett 2009; Endress 2010, 2015). Synorganisation is rare in basal angiosperms, but becomes an important trait in many monocot and eudicot flowers (Specht and Bartlett 2009), such as orchids (Vogel 1959; Rudall and Bateman 2002). It is hypothesized to be a key process in floral diversification (Endress 2006). The study of synorganised structures is 
challenging, and GM-oriented investigation may provide working hypotheses for an evo-devo exploration of such hyperorgan formation.

Although morphologically diverse, the flowers of Delphinieae Warm. (Ranunculaceae) are all based on a single relatively simple body plan. The calyx is petaloid with a dorsal sepal deformed into a pocket (spur or hood). The corolla is reduced to a single petal (nectariferous; in Consolida and Aconitella), a pair of petals (both nectariferous; in Aconitum and Gymnaconitum), or four petals (the two dorsal-most being nectariferous; in Delphinium and Staphisagria), located in the dorsal half of the flower. The nectariferous petals are made of three components: stalk, spur, and labium. The proportions of these three structures vary among the major clades of Delphinieae (e.g. the petal of Aconitum has a long stalk with a short spur and labium, whereas the petal of Delphinium has a very short stalk, a relatively long spur, and a short labium). The nectariferous petals are enclosed into the pocket of the dorsal sepal, which makes the dorsal part of Delphinieae flowers synorganised (Jabbour and Renner 2012a).

A (traditional) morphometric study of Delphinium floral shape using herbarium specimens was first conducted by Chartier et al. (2016), who measured 13 floral traits of afro-montane species and circumscribed three morphospecies, namely $D$. dasycaulon, $D$. leroyi and $D$. macrocentrum. We analyze here the floral shape of Delphinieae using GMM, in order to 1) assess the usefulness and effectiveness of geometric morphometrics on dry and compressed flowers from herbarium specimens, and 2) evaluate the diagnostic value of the dorsal module of the perianth (dorsal sepal + one dorsal petal) of the Delphinieae flower. Our preliminary study will help design future studies on the evo-devo of spur formation and the co-evolution of Delphinieae flowers with their pollinators.

\section{Materials and Methods}




\section{Definition of categories of flower morphologies and taxonomic sampling}

Delphinieae flowers can be classified into three morphological types: Aconitum, Delphinium and Consolida. Aconitum L., Delphinium L., and Consolida (DC.) Gray are three genera from the tribe Delphinieae (Fig. 1) that show contrasted floral morphologies, although they share the same floral groundplan (five petaloid sepals, the dorsal one enclosing the spurred petal(s) of the reduced corolla). The other three genera of Delphinieae can be associated with one of these three morphological types, as far as floral morphology is concerned.

In flowers of the type Aconitum, the dorsal sepal is hood-shaped or nightcap-shaped (Jabbour and Renner 2012a). It contains two dorsal petals, being usually hammer shaped with a long grooved stalk and a spurred limb (Kosuge and Tamura 1988). The limb consists of two parts, a labium and a spur. The spur is projected upward inside the upper hollowed sepal, often elongated and curved or coiled, but sometimes short and saccate (Kosuge and Tamura 1988). In flowers of the type Delphinium, the dorsal sepal is spurred and the corolla consists of four petals. The two dorsal nectariferous ones extend into the sepal spur, and the lateral ones, usually flat, cover the entrance of the spur. In flowers of the type Consolida, the sepal is spurred and the corolla consists of a single spurred petal that results from the postgenital fusion of the two dorsal-most petal primordia. The six other petal primordia have an arrested development (Jabbour and Renner 2012a).

The clades characterized by flowers from the type Aconitum are A. subg. Aconitum, A. subg. Lycoctonum, and Gymnaconitum gymnandrum. Until 2013, the genus Aconitum consisted of three subgenera: A. subg. Aconitum; A. subg. Lycoctonum, and A. subg. Gymnaconitum. Wang et al. (2013) stated that Gymnaconitum should be an independent genus based on molecular phylogenetic data. 
The clades characterized by flowers from the type Delphinium are D. subg. Delphinastrum \& Oligophyllon (hereafter called D. subg. Delphinastrum, for simplicity), D. subg. Anthriscifolium, D. subg. Delphinium, and Staphisagria.

The genera characterized by flowers from the type Consolida are Aconitella and Consolida. We follow here the same classification of Delphinieae as in Jabbour and Renner (2012b). The number of species sampled and the total number of species in each infratribal group is given between parentheses in Fig. 1.

\section{Digitization of herbarium specimens and selection of the photographs}

The specimens used in this study are from P (Herbier National, Muséum national d'Histoire naturelle, Paris) and KRA (Jagellonian University, Poland) herbaria. All photographs were taken by one of us (AN) based on an experimental protocol using a slab of LEDs that allows to trans-illuminate the herbarium specimens and obverse internal (i.e. hidden) floral structures (Fig. 2). All pictures were taken in a standardized way with a resolution of $3648 \times 2736$ pixels, and included a scale.

A total number of 2217 photographs were taken: 983 are from specimens with flowers of the type Aconitum and 1234 are from specimens with flowers of the type Delphinium (including the type Consolida, as Consolida and Aconitella specimens are often classified under Delphinium in the herbarium collections). Selecting a subset of photographs for our study was a two-step process. First, we selected the photographs that could be used for GMs, the socalled "good" photographs. A good photograph should meet two criteria: show clearly the internal structures and show a flower with as few folded structures as possible (Fig. 2). After this first step, we kept 43\% (423) and 38\% (469) of the photos of the flowers from the type Aconitum and Delphinium, respectively. The second step consisted in selecting 20 photographs (corresponding to 20 species) for each of the three categories of flowers, 
choosing the taxa in order for the sampling to be representative of the main clades in the phylogeny of Delphinieae (Fig. 1 and Suppl. Table 1). After sorting the specimens that could be used for GM, our sampling included a single type: voucher R. Gombault 1717 (P00197360), holotype of Consolida gombaultii (J. Thiébaut) Munz.

\section{Geometric morphometrics of dorsal sepal and petal}

We focused on the dorsal sepal and one dorsal petal, since these are the structures producing, protecting, and limiting the access to the nectar. The remaining parts of the dried flowers are often too folded to be morphometrically reliable and too dark even when trans-illuminated. As most of the Delphinieae (except Consolida and Aconitella) have a pair of dorsal petals, and as they are both very similar in shape and size (FJ, pers. obs.), we decided to work on only one dorsal petal.

To characterize the shape of these floral structures, we used a set of nine landmarks (three for the dorsal sepal and six for the dorsal petal; Fig. 3 and Suppl. Table 2) and seven series of 20 to 25 semilandmarks to capture the homologous curved outlines of the sepal and the petal between the landmarks (Gunz and Mitteroecker 2013). The coordinates of these landmarks and semilandmarks were manually recorded from the sixty photographs using the software tpsDig2 (Rohlf 2015). We decided not to consider the stalk of the petal in the analyses, as this structure is very slender in Aconitum, making it difficult to place the semilandmarks between the landmarks 4 and 5, and 4 and 9.

Analyses at different levels were performed (sepal and petal considered together or separately), but a similar protocol was followed for each of them. Flowers from the Consolida type were not included in the comparison of the dorsal module shape among Delphinieae, as their single petal is not homologous to any of the two dorsal petals from flowers from the Aconitum or Delphinium types. Landmark configurations were aligned using partial 
generalized Procrustes analysis (GPA; Rohlf and Slice 1990, Dryden and Mardia 1998) and semilandmarks were slid using the minimum bending energy criterion (Bookstein 1997) using tpsRelw (Rohlf 2015). Procrustes analysis extracts shape variation by filtering out the effects of size, position and orientation (e.g., Mitteroecker and Gunz 2009). Aligned coordinates were then orthogonally projected onto a linear, tangent shape space using the mean shape as point of tangency. All subsequent analyses were carried out on the tangent space coordinates. The main features of variation were highlighted by principal component analysis (PCA; Jolliffe 1986) and visually depicted by means of Thin-Plate Spline deformation grids (Bookstein 1989).

\section{Results}

Variation in the shape of the dorsal sepal + dorsal petal in each of the types Delphinium, Aconitum, and Consolida

Within each of the three types of dorsal floral module identified, namely Delphinium, Aconitum and Consolida, the quantitative capture of the shape of the dorsal sepal and of the dorsal petal allows to circumscribe well the different taxonomic subgroups (Fig. 4 and Supp. Fig. 1). In the Delphinium type, the principal components PC1 and PC2 together explain c. $64 \%$ of the shape variation in the dorsal floral module (Fig. 4A). Towards positive scores on $\mathrm{PC} 1$, the inner and outer spurs get narrower and the labium of the dorsal sepal covers more closely the labium of the dorsal petal. Along PC2, the inner and outer spurs get narrower and the inner spur tend to occupy more fully the cavity of the sepal spur. The labium of the dorsal sepal gets also better adjusted to the labium of the dorsal petal. The representatives of the genus Staphisagria (samples 1 and 2) are separated from the rest of the samples (23 to 40). The inner and outer spurs of Staphisagria flowers are wider, and the outer spur does not fit tightly around the inner spur. The rest of the samples belong to a grade of subgenera within 
the genus Delphinium: subg. Delphinium (samples 23 to 29), subg. Anthriscifolium (30), and subg. Delphinastrum (31 to 40). From the first cited subgenus to the third, the inner and outer spurs get wider and the labium of the dorsal sepal moves back from the labium of the dorsal petal. The sample corresponding to subg. Anthriscifolium (30) is morphologically closer from the samples belonging to subg. Delphinium than from subg. Delphinastrum. In the latter subgenus, samples are largely distributed across PC2, and hence show a high diversity of narrow and wide spurs, the outer one covering more or less tightly the inner one (Fig. 4A).

In the Aconitum type, the principal components PC1 and PC2 together explain c. $66 \%$ of the shape variation in the dorsal floral module (Supp. Fig. 1A). Towards positive scores on PC1, the dorsal sepal gets narrower and the limb of the dorsal sepal occupies a more vertical position within the hood. Along PC2, the spur and labium of the dorsal petal get narrower. The representatives of the subgenus Lycoctonum ( 3 to 9) are separated from the specimens belonging to subgenus Aconitum (10 to 21). The single specimen of the monotypic genus Gymnaconitum (22) occupies an extreme position in the PCA.

In the Consolida type, the principal components PC1 and PC2 together explain c. $62 \%$ of the shape variation in the dorsal floral module (Supp. Fig. 1B). Towards positive scores on PC1, the inner spur tends to occupy less fully the space within the outer spur. Along PC2, both outer and inner spurs get wider. The representatives of Aconitella (57 to 60) are separated from the specimens identified as Consolida s. str. (41 to 56).

\section{Variation in the shape of the dorsal sepal in Delphinieae}

In Delphinieae as a whole, the quantitative capture of the shape of the dorsal sepal allows to circumscribe well several taxonomic subgroups (Fig. 4B). PC1 and PC2 together explain c. $72 \%$ of the shape variation in the dorsal sepal. Along PC1, the spur gets wider and becomes hood-shaped and the rim of the labium becomes concave. Along PC2, the very wide (hood- 
shape) spur of the dorsal sepal gets narrower. Representatives of A. subg. Aconitum (10 to 21) form a homogenous group that is different from the rest of Delphinieae. The samples belonging to A. subg. Lycoctonum (3 to 9) and the genus Aconitella (57 to 60) occupy in the PCA an intermediary position between A. subg. Aconitum (10 to 21) and the rest of Delphinieae. The samples of Consolida (41 to 56) cluster together with the samples from the three subgenera of Delphinium (23 to 40). The two specimens of Staphisagria (1 and 2) cluster with a specimen of Consolida (43, C. armeniaca) and all three occupy an extreme position in the PCA (Fig. 4B).

\section{Variation in the shape of the dorsal petal in the Delphinium and Aconitum types}

In the species belonging to the Aconitum and Delphinium types, shape variation of the dorsal petal allows to circumscribe well the genera and subgenera (Fig. 4C). PC1 and PC2 together explain c. $73 \%$ of the shape variation in the dorsal petal. Along PC1, the middle part of the limb gets bigger and the spur gets down-curved. Along PC2, the labium of the petal gets more compact. The subgenera $A$. subg. Aconitum and A. subg. Lycoctonum cluster together and are isolated from the rest of the Delphinieae on the PCA. All the genera and subgenera belonging to the Delphinium type form the second cluster. The sampled species of Staphisagria, the sister genus to all the other Delphinieae, occupy an intermediary position between the cluster of Aconitum species and that of Delphinium species (Fig. 4C).

\section{Discussion}

\section{Geometric morphometrics of flowers from herbarium specimens}

Our study shows that, provided that a selection of the appropriate material is made, GMM are applicable to flowers from herbarium specimens. In the best cases, flowers are dried in such positions to show the taxonomically important features. However, in most cases, flowers are 
dried in random positions, with many floral parts folded. Selecting appropriate specimens is therefore a crucial prerequisite for generating exploitable photographs in the context of a morphometric study. We had to restrict our sampling in such a way that most of the type specimens we photographed were cast aside. We retained a single type specimen in our final sampling, that of C. gombaultii (see Material and Methods).

Our analyses of floral shapes in the three types based on variation vectors (vectors showing the major direction and intensity of shape variation around the consensus shape, among samples) generated by the tpsRelw software based on the set of samples we studied (result not shown) reveal that the shape of the labium of the dorsal sepal and of the dorsal petal seems much more variable than the shape of the spurs. We interpret this as an artifact due to the compression of the plant material in the process of making herbarium specimens. For this reason, we focus our discussion on the results relative to spur shape.

We here tested the applicability of GMM of herbarium specimens in a non-destructive way. While it could be interesting to compare our results with those obtained from fresh flowers, a study on herbarium and fresh leaves shows that, although the main conclusions were similar, the results were not strictly identical due to directional changes in shape changes, and that both kinds of material should not be considered together in a study (Tomaszewski and Górzkowska 2016).

\section{The dorsal module of Delphinieae flowers carries a strong phylogenetic signal}

The quantitative description of the flowers of Delphinieae confirms that the shapes of the dorsal sepal and of the dorsal petal(s) are taxonomically discriminant traits. Indeed, the shape of the dorsal module of the flower captured using landmarks and semilandmarks was sufficient to circumscribe the major infratribal clades (genera or subgenera) within Delphinieae. 
Our results suggest promising perspectives for the application of GMM in botanical taxonomic studies, as potentially new species can be placed in the space of the dorsal floral module shape. In this way, new species can be preliminarily attributed to a clade within Delphinieae, before confirming the result with morphological and molecular analyses. In the Delphinium type, three main clusters could be identified, which correspond to the genus Staphisagria, the subgenus Delphinastrum, and the subgenera Delphinium+Anthriscifolium, respectively (Fig. 4A). The shape of the dorsal module of Staphisagria flowers is very different from all the other shapes found in species with the Delphinium type. This is in accordance with the results of molecular phylogeny, which moved the three Staphisagria species out of the genus Delphinium (Jabbour and Renner 2011b, 2012b). Similarly, in the Aconitum and Consolida types, GM applied on the dorsal module of the flower allowed circumscribing the genera and the infragenerical groups (Supp. Fig. 1).

On the only graph gathering all the specimens of Delphinieae we studied (Fig. 4B), dorsal sepals from A. subg. Aconitum are different from all the other dorsal sepals of Delphinieae; they are characterized by a wide hooded shape. Flowers of $A$. subg. Lycoctonum belong to the other cluster, owing to the resemblance of their narrow-hooded dorsal sepal (nightcap-shaped; Jabbour and Renner 2012a) with the spurred dorsal sepal of the flowers of the Delphinium and Consolida types. Aconitella flowers occupy an intermediary position (although offcentered) between A. subg. Aconitum and the rest of Delphinieae flowers. Aconitella species genetically belong in the genus Delphinium sensu lato (including Consolida and Aconitella; Jabbour and Renner 2011b) but their flower morphology resembles that of $A$. subg. Lycoctonum flowers. This morphological similarity and evolutionary convergence obviously inspired the botanist who coined the genus name Aconitella (Spach 1839) and was highlighted by the one who subsequently updated the taxonomic treatment of the genus (Soják 1969). 


\section{Implications for evo-devo studies}

Spur initiation and development has been studied in some model species, such as Linaria (Plantaginaceae; Box et al. 2011) and Aquilegia (Ranunculaceae; Puzey et al. 2012; Yant et al. 2015). In columbines, the three-dimensional elaboration of the spur is initiated by localized, oriented cell divisions surrounding the incipient nectary. This process creates a pouch that is extended by anisotropic cell elongation (Puzey et al. 2012). Yant et al. (2015) hypothesized that the development of this evolutionary novelty could be promoted by nonmutually exclusive factors, including 1) prolonged, KNOX-dependent cell fate indeterminacy, 2) localized organ sculpting and/or 3) redeployment of hormone-signaling modules. Whether these three processes and anisotropic cell elongation are also at play during spur development in Delphinieae (belonging in Ranunculaceae as well) has still to be investigated. In addition, it would be interesting to study whether the molecular bases of sepal spur and petal spur development are similar or identical.

We observed that the inner spur(s) [the appendages of the dorsal petal(s)] differentially fit the space provided by the outer spur (the appendage of the dorsal sepal), depending on the species of Delphinieae considered. The development of the inner spur(s) can potentially constrain the development of the outer spur, and vice versa. We hypothesize that the constraints might be of genetic, hormonal, physical or mechanical origins.

This landmark-based investigation of Delphinieae flower shape diversity allows classifying the floral shapes into quasi-discrete categories, wherein species of interest could be targeted for evo-devo studies of spur development.

First step towards investigating the evolution of Delphinieae flowers with their pollinators 
Floral shape variation often reflects differences in plant pollination systems, particularly for plant species with specialized plant-pollinator interactions. Comparative studies have resulted in qualitative descriptions of these shape differences and multivariate analyses of floral trait measurements have, with varying degrees of success, shown that plant species can cluster in phenotype space according to general pollinator classes (Wilson et al. 2004; Bröderbauer, Weber, and Diaz 2013). However, in comparison to these traditional approaches, GMM have the potential to provide additional and more accurate insights into the associations between floral shape variation and pollination biology (van der Niet et al. 2010; Blanco-Pastor et al. 2015). Geometric morphometric analyses can enrich studies on the phenotypic evolution of flowers and of their pollinators. In the case of the spurred flowers of Delphinieae, for which the pollinators are expected to be specialists (but see Hollens et al. 2017;Vlašánková et al. 2017), comparing the form of the dorsal floral module with the front of the pollinator's body would allow testing the mutual fit of both structures. The collections (herbarium, entomological and ornithological) kept at natural history museums would be very useful in this respect.

\section{Acknowledgments}

We thank the Muséum national d'Histoire Naturelle, Paris, for funding the internship of Yiyun Chen (ATM funding), and the stay of AN as an invited researcher at Paris Herbarium in 2016. We also thank Sophie Nadot (Editor) and one anonymous reviewer for their critical and helpful comments.

\section{Disclosure statement}

No potential conflict of interest was reported by the authors. 


\section{Notes on contributors}

Yiyun Chen was an MSc student at the Muséum national d'Histoire Naturelle, Paris, and did her final year internship in 2017 under the supervision of Sylvain Gerber and Florian Jabbour. She is currently working in China in a governmental organization for the conservation of endangered species.

Florian Jabbour is an Associate Professor at the Muséum national d'Histoire Naturelle, Paris, and a curator at Paris Herbarium. His research focuses on the evolution of plant taxa and plant shapes. He is editor for Botany Letters. ORCID: 0000-0002-7729-1067.

Andriy V. Novikov is a Junior Research Scientist at the State Natural History Museum NASU in Lviv, Ukraine. His research focuses on vascular plant morphology, anatomy, taxonomy and chorology. ORCID: 0000-0002-0112-5070.

Wei Wang is an Associate Professor at the State Key Laboratory of Systematic and Evolutionary Botany, Institute of Botany, Chinese Academy of Sciences, Beijing. His research focuses on the systematics and evolution of angiosperms, and especially Ranunculales. He investigates temporal and spatial patterns of plant diversification by combining phylogenetic, biogeographic and molecular dating methods. ORCID: 0000-00016901-6375.

Sylvain Gerber is an Assistant Professor at the Muséum national d'Histoire Naturelle, Paris. His research focuses on large-scale morphological evolution and methods of statistical shape analysis. 
FJ, AN and SG designed the study. AN and YC generated the results, which were analyzed by YC, FJ and SG. FJ and SG wrote a first version of the manuscript. All co-authors contributed to the last version of the manuscript.

\section{References}

Abdelaziz, M., J. Lorite, A. J. Muñoz-Pajares, M. B. Herrador, F. Perfectti, and J. M. Gómez. 2011. "Using complementary techniques to distinguish cryptic species: a new Erysimum (Brassicaceae) species from North Africa.” American Journal of Botany 98 (6): 10491060. doi:10.3732/ajb.1000438.

Adams, D. C., F. J. Rohlf, and D. E. Slice. 2004. "Geometric morphometrics: ten years of progress following the 'revolution'.” Italian Journal of Zoology 71 (1): 5-16. doi:10.1080/11250000409356545.

Blanco-Pastor, J. L., C. Ornosa, D. Romero, I. M. Liberal, J. M. Gómez, and P. Vargas. 2015. "Bees explain floral variation in a recent radiation of Linaria." Journal of Evolutionary Biology 28 (4): 851-863. doi:10.1111/jeb.12609.

Bookstein, F. L. 1989. "Principal warps: Thin-plate splines and the decomposition of deformations." IEEE Transactions on Pattern Analysis and Machine Intelligence 11 (6): 567-585. doi:10.1109/34.24792.

Bookstein, F. L. 1997. Morphometric tools for landmark data: geometry and biology. Cambridge: Cambridge University Press.

Box, M. S., S. Dodsworth, P. J. Rudall, R. M. Bateman, and B. J. Glover. 2011. “Characterization of Linaria KNOX genes suggests a role in petal-spur development." The Plant Journal 68 (4): 703-714. doi:10.1111/j.1365313X.2011.04721.x. 
Bröderbauer, D., A. Weber, and A. Diaz. 2013. “The design of trapping devices in pollination traps of the genus Arum (Araceae) is related to insect type." Botanical Journal of the Linnean Society 172 (3): 385-397. doi:10.1111/boj.12054.

Chartier, M., S. Dressler, J. Schönenberger, A. Rojas Mora, C. Sarthou, W. Wang, and F. Jabbour. 2016. "The evolution of afro-montane Delphinium (Ranunculaceae): Morphospecies, phylogenetics and biogeography.” Taxon 65 (6): 1313-1327. doi:10.12705/656.6.

Cope, J. S., D. Corney, J. Y. Clark, P. Remagnino, and P. Wilkin. 2012. "Plant species identification using digital morphometrics: A review.” Expert Systems with Applications39 (8): 7562-7573. doi:10.1016/j.eswa.2012.01.073.

Dryden, I. L., and K. V. Mardia. 1998. Statistical analysis of shape. Chichester: Wiley.

Endress, P. K. 1994. Diversity and evolutionary biology of tropical flowers. Cambridge: Cambridge University Press.

Endress, P. K. 1999. "Symmetry in flowers: diversity and evolution.” International Journal of Plant Sciences 160 (S6): S3-S23. doi:10.1086/314211.

Endress, P. K. 2006. “Angiosperm floral evolution: morphological developmental framework." Advances in Botanical Research 44: 1-61. doi:10.1016/S00652296(06)44001-5.

Endress, P. K. 2010. "Synorganisation without organ fusion in the flowers of Geranium robertianum (Geraniaceae) and its not so trivial obdiplostemony." Annals of Botany 106 (5): 687-695. doi:10.1093/aob/mcq171.

Endress, P. K. 2015. "Development and evolution of extreme synorganization in angiosperm flowers and diversity: a comparison of Apocynaceae and Orchidaceae." Annals of Botany 117 (5): 749-767. doi:10.1093/aob/mcv119. 
Fernández-Mazuecos, M., J. L. Blanco-Pastor, J. M. Gómez, and P. Vargas. 2013. “Corolla morphology influences diversification rates in bifid toadflaxes (Linaria sect. Versicolores).” Annals of Botany 112 (9): 1705-1722. doi:10.1093/aob/mct214.

Gardner, A. G., J. N. Fitz Gerald, J. Menz, K. A. Shepherd, D. G. Howarth, and R. S. Jabaily. 2016. "Characterizing floral symmetry in the Core Goodeniaceae with geometric morphometrics.” PLoS one 11 (5): e0154736. doi:10.1371/journal.pone.0154736.

Gómez, J. M., F. Perfectti, and J. P. M. Camacho. 2006. "Natural selection on Erysimum mediohispanicum flower shape: insights into the evolution of zygomorphy." The American Naturalist 168 (4): 531-545. doi:10.1086/507048.

Gunz, P., and P. Mitteroecker. 2013. "Semilandmarks: a method for quantifying curves and surfaces.” Hystrix 24 (1): 103-109. doi:10.4404/hystrix-24.1-6292.

Hollens, H., T. van der Niet, R. Cozien, and M. Kuhlmann. 2017. “A spur-ious inference: pollination is not more specialized in long-spurred than in spurless species in DiasciaRediviva mutualisms.” Flora 232: 73-82. doi:10.1016/j.flora.2016.12.006.

Jabbour, F., and S. S. Renner. 2011a. "Resurrection of the genus Staphisagria J. Hill, sister to all the other Delphinieae (Ranunculaceae)." PhytoKeys 7: 21-26. doi:10.3897/phytokeys.7.2010. doi:10.3897/phytokeys.7.2010.

Jabbour, F., and S. S. Renner. 2011b. "Consolida and Aconitella are an annual clade of Delphinium (Ranunculaceae) that diversified in the Mediterranean basin and the IranoTuranian region.” Taxon 60 (4): 1029-1040.

Jabbour, F., and S. S. Renner. 2012a. "Spurs in a spur: perianth evolution in the Delphinieae (Ranunculaceae).” International Journal of Plant Sciences 173 (9): 1036-1054. doi:10.1086/667613.

Jabbour, F., and S. S. Renner. 2012b. “A phylogeny of Delphinieae (Ranunculaceae) shows that Aconitum is nested within Delphinium and that Late Miocene transitions to long life 
cycles in the Himalayas and Southwest China coincide with bursts in diversification." Molecular Phylogenetics and Evolution 62 (3): 928-942. doi:10.1016/j.ympev.2011.12.005.

Jacques, F., and Z. Zhou. 2010. "Geometric morphometrics: a powerful tool for the study of shape evolution in Menispermaceae endocarps.” Taxon 59 (3): 881-895.

Jensen, R. J., K. M. Ciofani, and L. C. Miramontes. 2002. "Lines, outlines, and landmarks: morphometric analyses of leaves of Acer rubrum, Acer saccharinum (Aceraceae) and their hybrid.” Taxon 51 (3): 475-492.doi:10.2307/1554860.

Jolliffe, I. T. 1986. "Principal Component Analysis and Factor Analysis.” Chap. 6 in Principal component analysis. New York: Springer-Verlag New York.

Kosuge, K., and M. Tamura. 1988. "Morphology of the petal in Aconitum." Journal of Plant Research 101 (3): 223-237. doi:10.1007/BF02488601.

Mitteroecker, P., and P. Gunz. 2009. “Advances in geometric morphometrics.” Evolutionary Biology 36 (2): 235-247. doi:10.1007/s11692-009-9055-x.

Nagahama, N., A. M. Anton, and G. A. Norrmann. 2014. "Taxon delimitation in the Andropogon lateralis complex (Poaceae) in southern South America based on morphometrical analyses." Systematic Botany 39 (3): 804-813. doi:10.1600/036364414X681509.

Puzey, J. R., S. J. Gerbode, S. A. Hodges, E. M. Kramer, and L. Mahadevan. 2012. "Evolution of spur-length diversity in Aquilegia petals is achieved solely through cellshape anisotropy." Proceedings of the Royal Society of London B: Biological Sciences 279 (1733): 1640-1645. doi:10.1098/rspb.2011.1873.

Rohlf, F. J. 2015. “The tps series of software.” Hystrix, the Italian Journal of Mammalogy 26 (1): 9-12. 
Rohlf, F. J., and L. F. Marcus. 1993. “A revolution morphometrics.” Trends in Ecology \& Evolution 8 (4): 129-132. doi:10.1016/0169-5347(93)90024-J.

Rohlf, F. J., and D. Slice. 1990. "Extensions of the Procrustes method for the optimal superimposition of landmarks." Systematic Biology 39 (1): 40-59. doi:10.2307/2992207.

Rudall, P. J., and R. M. Bateman. 2002. "Roles of synorganisation, zygomorphy and heterotopy in floral evolution: the gynostemium and labellum of orchids and other lilioid monocots.” Biological Reviews 77(3): 403-441. doi:10.1017/S1464793102005936.

Sauquet, H., M. von Balthazar, S. Magallón, J. A. Doyle, P. K. Endress, E. J. Bailes, E. Barroso de Morais et al. 2017. "The ancestral flower of angiosperms and its early diversification." Nature Communications 8: 16047. doi:10.1038/ncomms16047.

Savriama, Y., J. M. Gómez, F. Perfectti, and C. P. Klingenberg. 2012. “Geometric morphometrics of corolla shape: dissecting components of symmetric and asymmetric variation in Erysimum mediohispanicum (Brassicaceae).” New Phytologist 196 (3): 945-954. doi:10.1111/j.1469-8137.2012.04312.x.

Shipunov, A. B., and R. M. Bateman. 2005. "Geometric morphometrics as a tool for understanding Dactylorhiza (Orchidaceae) diversity in European Russia.” Biological Journal of the Linnean Society 85 (1): 1-12. doi:10.1111/j.1095-8312.2005.00468.x.

Soják, J. 1969. “Aconitella Spach, eine vergessene Gattung der Familie Ranunculaceae." Folia Geobotanica 4 (4): 447-449.

Spach, E. 1839. “Genre Aconitelle. - Aconitella Spach.” In Histoire Naturelle des Végétaux. Phanérogames VII, 358-360. Paris: Librairie Encyclopédique de Roret. 
Specht, C. D., and M. E. Bartlett. 2009. "Flower evolution: the origin and subsequent diversification of the angiosperm flower." Annual Review of Ecology Evolution and Systematics 40: 217-243. doi:10.1146/annurev.ecolsys.110308.120203.

Tomaszewski, D., and A. Górzkowska. 2016. "Is shape of a fresh and dried leaf the same?" PloS one 11 (4): e0153071. doi:10.1371/journal.pone.0153071.

van der Niet, T., C. P. E. Zollikofer, M. S. Ponce de León, S. D. Johnson, and H. P. Linder. 2010. "Three-dimensional geometric morphometrics for studying floral shape variation.” Trends in Plant Science 15 (8): 423-426. doi:10.1016/j.tplants.2010.05.005.

Viscosi, V., and A. Cardini. 2011. "Leaf morphology, taxonomy and geometric morphometrics: a simplified protocol for beginners." PLoS One 6 (10): e25630. doi:10.1371/journal.pone.0025630.

Vlašánková, A., E. Padyšáková, M. Bartoš, X. Mengual, P. Janečková, and Š Janeček. 2017. "The nectar spur is not only a simple specialization for long-proboscid pollinators.” New Phytologist 215 (4): 1574-1581. doi:10.1111/nph.14677.

Vogel, S. 1959. “Organographie der Blüten kapländischer Ophrydeen.”Akademie der Wissenchaften und der Literatur, Abhandlungen der MathematischNaturwissenschaftlichen Klasse 67: 6-7.

Wang, C. N., H. C. Hsu, C. C. Wang, T. K. Lee, and Y. F. Kuo. 2015. “Quantifying floral shape variation in 3D using microcomputed tomography: a case study of a hybrid line between actinomorphic and zygomorphic flowers." Frontiers in Plant Science 6: 724. doi:10.3389/fpls.2015.00724.

Wang, W., Y. Liu, S. X. Yu, T. G. Gao, and Z. D. Chen. 2013. “Gymnaconitum, a new genus of Ranunculaceae endemic to the Qinghai-Tibetan Plateau.” Taxon 62 (4): 713-722. doi:10.12705/624.10. 
Wilson, P., M. C. Castellanos, J. N. Hogue, J. D. Thomson, and W. S. Armbruster. 2004. “A multivariate search for pollination syndromes among penstemons." Oikos 104 (2): 345361. doi:10.1111/j.0030-1299.2004.12819.x.

Xiang, K. L., Z. Aytaç, Y. Liu, F. Espinosa, F. Jabbour, J. W. Byng, C. F. Zhang, A. S. Erst, and W. Wang. 2017. "Recircumscription of Delphinium subg. Delphinium (Ranunculaceae) and implications for its biogeography.” Taxon 66 (3): 554-566. doi:10.12705/663.3.

Yant, L., S. Collani, J. Puzey, C. Levy, and E. M. Kramer. 2015. "Molecular basis for threedimensional elaboration of the Aquilegia petal spur." Proceedings of the Royal Society of London B: Biological Sciences 282 (1803): 20142778. doi:10.1098/rspb.2014.2778. 


\section{Figure legends}

Figure 1. Synthetic molecular phylogeny of the tribe Delphinieae based on the works of Jabbour and Renner (2011a, 2011b, 2012a, 2012b), Wang et al. (2013) and Xiang et al. (2017). The same colour code is used in Fig. 4, Supp. Fig. 1 and Supp. Table 1. The number of species sampled and the total number of species in each infratribal group is given between parentheses.

Figure 2. Images of the dried flowers used for the geometric morphometric analyses. (A-C) Images of the full herbarium specimens. Digital images of the specimens can be visualized and downloaded using the following link:

https://science.mnhn.fr/institution/mnhn/collection/p/item/search/form. (D - F) Focus on the flowers that were analyzed. $(\mathrm{G}-\mathrm{I})$ the same flowers, trans-illuminated. $(\mathrm{J}-\mathrm{L})$ The corresponding corolla of each flower type. The nectar spurs are indicated in orange. The petal primordia with an arrested development are represented with grey half disks.

Figure 3. Position of the landmarks for the three flower types. (A) Aconitum type. (B) Consolida type. (C) Delphinium type.

Figure 4. 2D geometric morphometric analysis of floral shape variation in the tribe Delphinieae. Virtual flower shapes and deformation grids were produced to visualize the modes of floral shape variation along PC1 and PC2. The list of species names corresponding to the numbers in the Principal Component Analysis (PCA) is given in Supp. Table 1. The same colour code is used in Fig. 1, Supp. Fig. 1 and Supp. Table 1. (A) PCA of the variation in the shape of the dorsal module of the flowers from the type Delphinium. (B) PCA of the 
variation in the shape of the dorsal sepal of the flowers from all the genera and subgenera of Delphinieae. (C) PCA of the variation in the shape of the dorsal petal of the flowers from the types Delphinium and Aconitum.

Supplementary Figure 1. 2D geometric morphometric analysis of floral shape variation in the tribe Delphinieae. Virtual flower shapes and deformation grids were produced to visualize the modes of floral shape variation along PC1 and PC2. The list of species names corresponding to the numbers in the Principal Component Analysis (PCA) is given in Supp. Table 1. The same colour code is used in Fig. 1 and 4 and Supp. Table 1. (A) PCA of the variation in the shape of the dorsal module of the flowers from the type Aconitum. (B) PCA of the variation in the shape of the dorsal module of the flowers from the type Consolida.

Supplementary Table 1. List of species and specimens (barcodes) sampled, and associated flower type. Genera and subgenera ordered as in the phylogenetic tree (bottom-up). Within a subgenus or genus, species are ordered alphabetically. We follow here the same classification of Delphinieae as in Jabbour and Renner (2012b). The same colour code is used in Fig. 1 and 4 and Supp. Fig. 1. "(H)" next to the barcode indicates that the specimen is the holotype of the species name. Digital images of the specimens can be visualized and downloaded using the following link: https://science.mnhn.fr/institution/mnhn/collection/p/item/search/form

Supplementary Table 2. Description of landmarks used for Delphinieae flowers. 
Aconitella (4/c. 12)

Consolida (14/c. 60)

Consolida (2/3)

Delphinium subg. Delphinastrum \& Oligophyllon (10/c. 300)

Delphinium subg. Anthriscifolium (1/1)

Delphinium subg. Delphinium (7/c. 18)

Gymnaconitum gymnandrum (1/1)

2 Aconitum subg. Aconitum (12/c. 250) Aconitum subg. Lycoctonum (7/c. 50) 


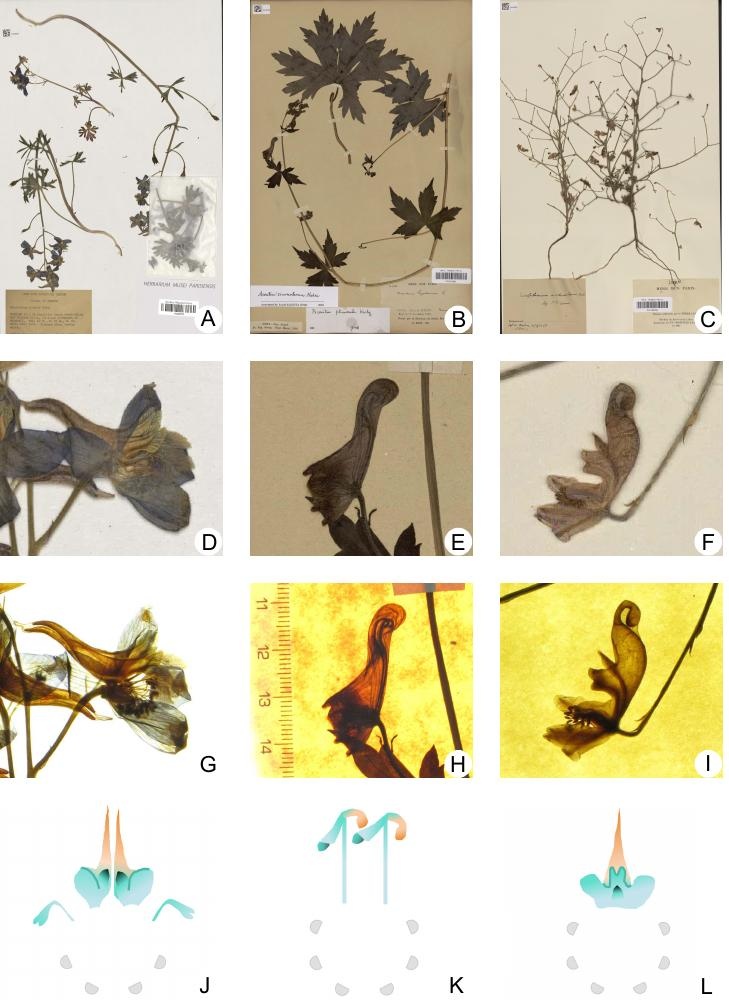

Delphinium type 


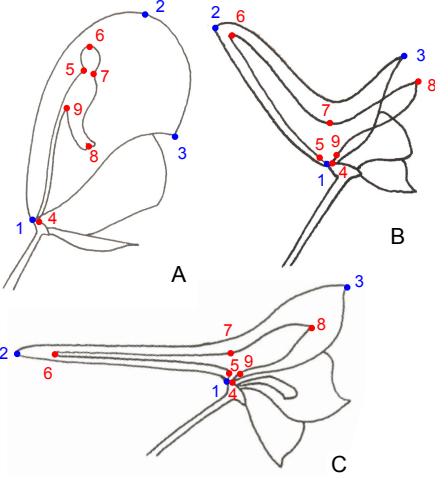



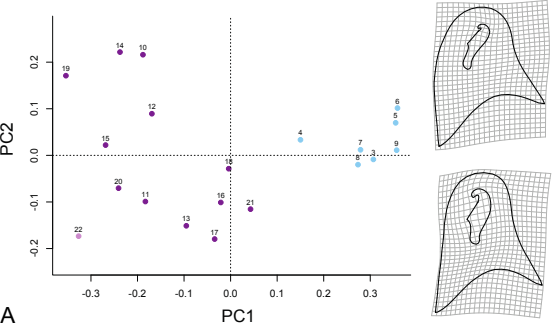

PC1 (53.76\%)
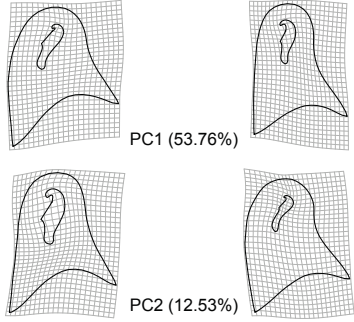

PC2 (12.53\%)
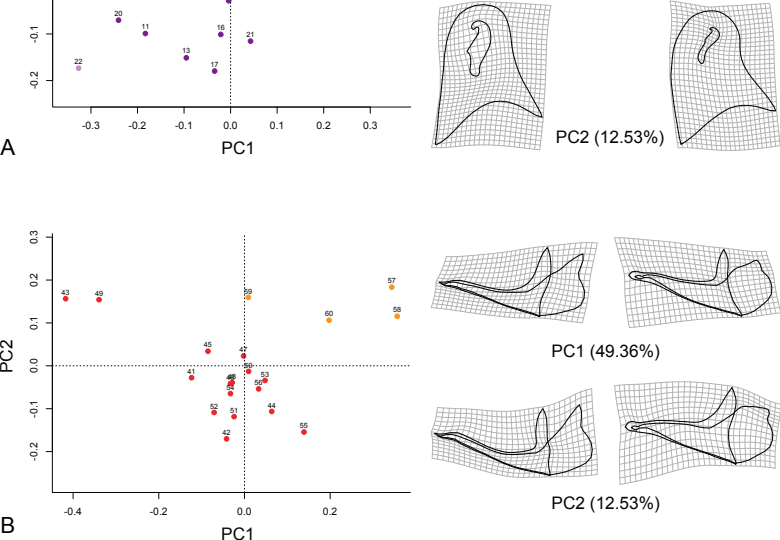

PC1 (49.36\%)
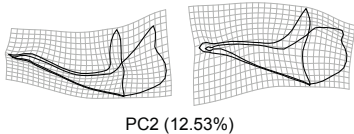
Supplementary Table 1: List of species and specimens (barcodes) sampled, and associated flower type. Genera and subgenera ordered as in the phylogenetic tree (bottom-up). Within a subgenus or genus, species are ordered alphabetically. We follow here the same classification of Delphinieae as in Jabbour and Renner (2012b). "(H)” next to the barcode indicates that the specimen is the holotype of the species name. Digital images of the specimens can be visualized and downloaded using the following link:

https://science.mnhn.fr/institution/mnhn/collection/p/item/search/form

\begin{tabular}{|c|c|c|c|c|c|}
\hline Id. & Genus & Subgenus & Species & Barcode & Flower type \\
\hline 1 & Staphisagria & - & S. picta (Willd.) Jabbour & P00249053 & Delphinium \\
\hline 2 & Staphisagria & - & S. requienii (DC.) Spach & P02548605 & Delphinium \\
\hline 3 & Aconitum & Lycoctonum & A. alboviolaceum Kom. & P00201311 & Aconitum \\
\hline 4 & Aconitum & Lycoctonum & A. kirinense Nakai & KRA002618 & Aconitum \\
\hline 5 & Aconitum & Lycoctonum & A. lycoctonum L. & P02344462 & Aconitum \\
\hline
\end{tabular}




\begin{tabular}{|c|c|c|c|c|c|}
\hline 6 & Aconitum & Lycoctonum & A. scaposum Franch. & P00201802 & Aconitum \\
\hline 7 & Aconitum & Lycoctonum & A. septentrionale Koelle & P02344871 & Aconitum \\
\hline 8 & Aconitum & Lycoctonum & A. sinomontanum Nakai & P00201961 & Aconitum \\
\hline 9 & Aconitum & Lycoctonum & A. umbrosum (Korsh.) Kom. & P00130996 & Aconitum \\
\hline 10 & Aconitum & Aconitum & A. anthora $\mathrm{L}$. & P00601109 & Aconitum \\
\hline 11 & Aconitum & Aconitum & A. ambiguum Rchb. & P00601133 & Aconitum \\
\hline 12 & Aconitum & Aconitum & A. anthoroideum DC. & P00201341 & Aconitum \\
\hline 13 & Aconitum & Aconitum & A. columbianum Nutt. & P02311719 & Aconitum \\
\hline 14 & Aconitum & Aconitum & A. delphinifolium DC. & P02311696 & Aconitum \\
\hline 15 & Aconitum & Aconitum & A. falciforme Hand.-Mazz. & P02681883 & Aconitum \\
\hline 16 & Aconitum & Aconitum & A. japonicum Thunb. & KRA003614 & Aconitum \\
\hline
\end{tabular}




\begin{tabular}{|c|c|c|c|c|c|}
\hline 17 & Aconitum & Aconitum & A. kusnezoffii Rchb. & P00201703 & Aconitum \\
\hline 18 & Aconitum & Aconitum & A. macrorhynchum Turcz. ex Ledeb. & P00201813 & Aconitum \\
\hline 19 & Aconitum & Aconitum & A. napellus $\mathrm{L}$. & P02721475 & Aconitum \\
\hline 20 & Aconitum & Aconitum & A. polyanthum (Finet \& Gagnep.) Hand.-Mazz. & P00201941 & Aconitum \\
\hline 21 & Aconitum & Aconitum & A. villosum Rchb. & P00200041 & Aconitum \\
\hline 22 & Gymnaconitum & - & G. gymnandrum (Maxim.) Wei Wang \& Z.D. Chen & P02548433 & Aconitum \\
\hline 23 & Delphinium & Delphinium & D. balansae Boiss. \& Reut. & P02336021 & Delphinium \\
\hline 24 & Delphinium & Delphinium & D. gracile DC. & P02482028 & Delphinium \\
\hline 25 & Delphinium & Delphinium & D. halteratum Sibth. \& Sm. & P02379289 & Delphinium \\
\hline 26 & Delphinium & Delphinium & D. nanum DC. & P02819166 & Delphinium \\
\hline 27 & Delphinium & Delphinium & D. obcordatum DC. & P02379235 & Delphinium \\
\hline
\end{tabular}




\begin{tabular}{|c|c|c|c|c|c|}
\hline 28 & Delphinium & Delphinium & D. peregrinum L. & P02379156 & Delphinium \\
\hline 29 & Delphinium & Delphinium & D. verdunense Balb. & P03169199 & Delphinium \\
\hline 30 & Delphinium & Anthriscifolium & D. anthriscifolium Hance & P03263966 & Delphinium \\
\hline 31 & Delphinium & Delphinastrum \& Oligophyllon & D. bicolor Nutt. & P02481573 & Delphinium \\
\hline 32 & Delphinium & Delphinastrum \& Oligophyllon & D. cardinale Hook. & P02311302 & Delphinium \\
\hline 33 & Delphinium & Delphinastrum \& Oligophyllon & D. decorum Fisch. \& C.A. Mey. & P02311215 & Delphinium \\
\hline 34 & Delphinium & Delphinastrum \& Oligophyllon & D. depauperatum Nutt. & P02481532 & Delphinium \\
\hline 35 & Delphinium & Delphinastrum \& Oligophyllon & D. elatum L. & P02471422 & Delphinium \\
\hline 36 & Delphinium & Delphinastrum \& Oligophyllon & D. emarginatum C. Presl & P02481517 & Delphinium \\
\hline 37 & Delphinium & Delphinastrum \& Oligophyllon & D. gracilentum Greene & P02311048 & Delphinium \\
\hline 38 & Delphinium & Delphinastrum \& Oligophyllon & D. grandiflorum $\mathrm{L}$. & P02396378 & Delphinium \\
\hline
\end{tabular}




\begin{tabular}{|c|c|c|c|c|c|}
\hline 39 & Delphinium & Delphinastrum \& Oligophyllon & D. hesperium A. Gray & P02311233 & Delphinium \\
\hline 40 & Delphinium & Delphinastrum \& Oligophyllon & D. pentagynum Lam. & P02379842 & Delphinium \\
\hline 41 & Consolida & - & C. ajacis (L.) Schur & P02336054 & Consolida \\
\hline 42 & Consolida & - & C. armeniaca (Stapf ex Huth) Schrödinger & P00197473 & Consolida \\
\hline 43 & Consolida & - & C. axilliflora (DC.) Schrödinger & P00195897 & Consolida \\
\hline 44 & Consolida & - & C. camptocarpa (Fisch. \& C.A. Mey.) Nevski & P00197033 & Consolida \\
\hline 45 & Consolida & - & C. deserti-syriaci (Zohary) Munz & P00197326 & Consolida \\
\hline 46 & Consolida & - & C. divaricata (Ledeb.) Schrödinger & P00197219 & Consolida \\
\hline 47 & Consolida & - & C. flava (DC.) Schrödinger ex Hand.-Mazz. & P00197325 & Consolida \\
\hline 48 & Consolida & - & C. glandulosa (Boiss. \& A. Huet) Bornm. & P00197354 & Consolida \\
\hline 49 & Consolida & - & C. gombaultii (J. Thiébaut) Munz & P00197360 (H) & Consolida \\
\hline
\end{tabular}




\begin{tabular}{|c|c|c|c|c|c|}
\hline 50 & Consolida & - & C. mauritanica (Coss.) Munz & P02336109 & Consolida \\
\hline 51 & Consolida & - & C. olopetala Hayek & P00198564 & Consolida \\
\hline 52 & Consolida & - & C. orientalis Schrödinger & P02467591 & Consolida \\
\hline 53 & Consolida & - & C. pubescens Soó & P02379356 & Consolida \\
\hline 54 & Consolida & - & C. regalis Gray & P02581589 & Consolida \\
\hline 55 & Consolida & - & C. rugulosa Schrödinger & P02481582 & Consolida \\
\hline 56 & Consolida & - & C. tenuissima Soó & P02575637 & Consolida \\
\hline 57 & Aconitella & - & A. aconiti (L.) Soják & P00195719 & Consolida \\
\hline 58 & Aconitella & - & A. anthoroidea (Boiss.) Soják & P00195782 & Consolida \\
\hline 59 & Aconitella & - & A. barbata (Bunge) Soják & P00195914 & Consolida \\
\hline 60 & Aconitella & - & A. hohenackeri (Boiss.) Soják & P02481578 & Consolida \\
\hline
\end{tabular}


Supplementary Table 2: Description of landmarks used for Delphinieae flowers

\begin{tabular}{|c|c|c|}
\hline Organ & Landmark & Position \\
\hline \multirow[t]{3}{*}{ Dorsal sepal } & 1 & Junction of the receptacle with the dorsal sepal \\
\hline & 2 & Apex (the most distant point from $\mathrm{S} 1$ ) \\
\hline & 3 & Tip of the labium \\
\hline \multirow[t]{6}{*}{ Dorsal petal } & 4 & Junction of the receptacle with the petal stalk \\
\hline & 5 & Junction of the stalk with the spur \\
\hline & 6 & Apex of the spur \\
\hline & 7 & Junction of the spur with the labium \\
\hline & 8 & Tip of the labium \\
\hline & 9 & Junction of the labium with the stalk \\
\hline
\end{tabular}

